\title{
Treatment challenges in pediatric Cushing's disease: Review of the literature with particular emphasis on predictive factors for the disease recurrence
}

\author{
Katarzyna Pasternak-Pietrzak (i) ${ }^{1} \cdot$ Elżbieta Moszczyńska ${ }^{1} \cdot$ Mieczysław Szalecki ${ }^{1,2}$
}

Received: 16 April 2019 / Accepted: 26 July 2019

(c) The Author(s) 2019

\begin{abstract}
Cushing's disease (CD) is a rare endocrine condition caused by a corticotroph pituitary tumor that produces adrenocorticotropic hormone. The current state of knowledge of $\mathrm{CD}$ treatment is presented in this article including factors that can be helpful in predicting remission and/or recurrence of the disease. The primary goals in CD treatment are quick diagnosis and effective, prompt treatment as the persistent disease is associated with increased morbidity and mortality. Cooperation of a team consisting of experienced pediatrician/adult endocrinologist, neuroradiologist, transsphenoidal neurosurgeon and (if necessary) radiotherapist contribute to the best treatment effects.
\end{abstract}

Keywords Cushing's disease $\cdot$ Pituitary adenoma $\cdot$ Hypopituitarism $\cdot$ Adenomectomy $\cdot$ Transsphenoidal surgery

$\begin{array}{ll}\text { Abbreviations } \\ \text { ACTH } & \text { adrenocorticotropin } \\ \text { CD } & \text { Cushing's disease } \\ \text { CRH } & \text { corticotrophin } \\ \text { CS } & \text { Cushing's syndrome } \\ \text { HPAA } & \text { hypothalamic-pituitary-adrenal axis } \\ \text { min. } & \text { minimum } \\ \text { mos. } & \text { months } \\ \text { MRI } & \text { magnetic resonance imaging } \\ \text { o } & \text { ovine } \\ \text { RT } & \text { radiotherapy } \\ \text { TSS } & \text { transsphenoidal surgery } \\ \text { yrs } & \text { years }\end{array}$

Katarzyna Pasternak-Pietrzak

kasia.a.pasternak@gmail.com

1 Department of Endocrinology and Diabetology, The Children's Memorial Health Institute (CMHI), Al. Dzieci Polskich 20, 04-730 Warsaw, Poland

2 The Medicine and Health Sciences Faculty, University of Jan Kochanowski, Al. IX Wieków Kielc 19A, 25-317 Kielce, Poland

\section{Introduction}

Cushing's disease $(\mathrm{CD})$ results from excess production of adrenocorticotropic hormone (ACTH) by pituitary adenoma [1]. The early intervention with effective treatment is crucial to prevent the consequences of long-term hypercortisolaemia [2]. The first-line treatment is pituitary surgery performed by transsphenoidal approach [3]. Remission rates in pediatric population vary depending on a center, neurosurgeon's experience and other factors, and are reported to be between 45-95\% [4-9]. In the case of relapse, second pituitary surgery or radiotherapy (RT) are considered. Pharmacological treatment is helpful in controlling hypercortisolemia during preparation for surgery or in case of refusal of surgical treatment and whilst awaiting the radiotherapy effects [10]. Herein, the current state of knowledge of CD treatment is presented together with description of predictive factors for $\mathrm{CD}$ recurrence. The article focuses on $\mathrm{CD}$ treatment of children and presents the comparison with the adult population highlighting the differences between these 2 groups of $C D$ patients.

\section{Transsphenoidal surgery}

Transsphenoidal surgery (TSS) is a first-line therapy of CD. The procedure is regarded as a safe and effective method as a selective microadenomectomy gives the possibility to 
preserve pituitary functions $[3,11,12]$. The technical difficulty of TSS results from the small sizes of ACTHsecreting adenomas and the pituitary fossa as well as from absent aeration of the sphenoid bone in young patients [13], hence the success of TSS depends on the surgeon's expertize.

There are 2 different techniques of pituitary TSS: microscopic and endoscopic $[14,15]$. The first one uses the standard microscopic transseptal approach popularized by Hardy in the late 1960s [14]. Thanks to microscopic threedimensional visualization, operating in three-dimensional space is possible [15]. Endoscopic TSS, used first in adults since late 1990s, enables visualization of structures that are not in the direct line of vision (e.g., opticocarotid recesses, suprasellar areas) [16]. The drawback of this technique is two-dimensionality which impairs depth perception [16]. The endoscopic approach has given very good results in the treatment of pediatric patients with $\mathrm{CD}$ from the London center [17]: 5 of 6 patients were cured (remission rate $83.3 \%$ ) and in $50 \%$ of them pituitary adenoma was not detected, while no tumor identification at TSS is regarded as poor predictor of remission rate [17]. Transcranial approach is no longer used as a primary technique and is performed only when the transsphenoidal approach is not possible or tumor size, its localization, and expansion requires this technique $[2,18,19]$.

During the early weeks after TSS, neurosurgeons as well as endocrinologists should remember about possible complications that may occur such as: transient diabetes insipidus, hypopituitarism and, less frequently, syndrome of inappropriate antidiuretic hormone secretion or visual loss [20]. They are more often in the case of macroadenomas and extensive pituitary exploration [2, 19, 21]. Permanent pituitary dysfunction and diabetes insipidus are rare. Central hypothyroidism, GH deficiency or hypogonadism may also occur $[20,22]$. The patients who require repeated transsphenoidal surgery are more likely to have complications such as: permanent diabetes insipidus, cerebrospinal fluid rhinorrhea, hemorrhage, injury of internal carotid, cranial nerve palsy and meningitis [23]. The mortality rate after TSS is low $(<1 \%)[20,24]$.

The loss of pituitary function depends on the aggressiveness of surgery; mean rates of hypopituitarism in adults range from $6.6 \%$ (selective adenomectomy) to $80.2 \%$ (total hypophysectomy) [1]. Post-TSS hypothyroidism occurs in $3.1-68.8 \%$, hypogonadism in $0.6-46.1 \%$, GH deficiency in $0.6-52.8 \%$ and panhypopituitarism in $1.4-29.3 \%$ of adult patients [1]. Data on pituitary function in long-term postTSS assessment in children is limited comparing to data on adult patients. The examples of available limited pediatric literature review come from the centers in London and Bethesda [25, 26]. The London center provides data on the occurrence of long-term growth hormone deficiency (GHD) in $44 \%$ of patients (4/9 investigated), long-term hypogonadotropic hypogonadism (HH) in 19\% of patients (all adults) and long-term panhypopituitarism in $19 \%$ of patients after effective surgical treatment ( 21 children, mean followup $10.6 \mathrm{yrs}$ ) [25]. For comparison, the National Institute of Health in Bethesda has published data based on much shorter mean time of follow-up (22 months) about the occurrence of secondary hypothyroidism in $16 \%$, diabetes insipidus in $8 \%$, GHD in $8 \%$ and $\mathrm{HH}$ in $3 \%$ of patients (50 children) [26].

\section{Cure of Cushing's disease and predictors for remission}

There is no consensus on the criteria for $\mathrm{CD}$ remission $[2,19,21]$. Different criteria used to establish CD remission or cure make the comparison of the treatment outcome in different studies difficult [1]. Furthermore, the results of studies evaluating mainly outcome of TSS cannot be adapted to different $\mathrm{CD}$ therapies [1]. Also the meaning of 'remission' of the disease is not unequivocal: there is temporary disease cure after TSS, when an apparent cure of the disease may be followed by a recurrence (which can be years or even decades after TSS) and a definitive disease cure when there is no relapse in long-term follow up [1].

\section{Postsurgical morning serum cortisol}

Postsurgical morning serum cortisol is the most important marker to assess remission after TSS [27-29]. Recommended time when it should be measured varies depending on the center. Most authors suggest several measurements within 2 weeks after TSS, usually 5-14 days after surgery [21, 30, 31].

However, Atkinson et al. emphasize that the $0900 \mathrm{~h}$ serum cortisol may fall with time after surgery, sometimes over a few weeks [32]. For this reason other authors suggest that the serum cortisol measurement 1 to 6 months after TSS is better to establish the cure [33, 34]. Furthermore, mild or cyclical hypercortisolism may complicate the interpretation of TSS results [32].

Most studies in adults show long-term remission if postoperative (within 7 days after TSS) cortisol concentrations are $<138 \mathrm{nmol} / \mathrm{L}(<5 \mu \mathrm{g} / \mathrm{dL})[2,19,21]$. The study by Trainer et al. gave the concept of more strict remission criteria: an undetectable $(<1.8 \mu \mathrm{g} / \mathrm{dl}(50 \mathrm{nmol} /$ liter $))$ postoperative $0900 \mathrm{~h}$ serum cortisol [35]. In this study in 20 of 48 adult patients after TSS for CD postoperative $0900 \mathrm{~h}$ serum cortisol was undetectable and in none of these patients the disease recurred (follow-up 40 months) [35]. Strict criteria are used more widely in children: serum cortisol $<1.8 \mu \mathrm{g} / \mathrm{dl}(<50 \mathrm{nmol} / \mathrm{l})$ at $0900 \mathrm{~h}$ within 2 weeks 
after surgery (cortisol measured 3-14 days after surgery) $[13,21,30-32,36]$. It is important to withhold glucocorticoids treatment before cortisol measuring (min. 24-h break from the last dose of hydrocortisone (HC)) or to use low doses of dexamethasone (Dx) $(<1 \mathrm{mg})$ [1].

It is noteworthy that no cortisol value (nor undetectable, nor subnormal) gives $100 \%$ certainty of no relapse [37, 38]. Alexandraki [28] has shown in the study of 131 adult CD patients that strict remission criteria were not superior in terms of the probability of recurrence compared with postoperative normocortisolaemia. Similarly, interesting conclusions can be drawn from the study by Lindsay et al. [37] of 331 patients (children and adults) with CD after TSS divided to 2 groups: group 1 -patients with subnormal postoperative cortisol $(2-4.9 \mu \mathrm{g} / \mathrm{dl})$ and group 2-patients with postoperative cortisol $<2 \mu \mathrm{g} / \mathrm{dl}$. It was hypothesized that patients with subnormal cortisol (group 1) might achieve long-term remission: the results showed that longterm remission rates were similar in 2 groups $(2 \mu \mathrm{g} / \mathrm{dl}$, $9.5 \% ; 5 \mu \mathrm{g} / \mathrm{dl}, 10.4 \% ; 2-4.9 \mu \mathrm{g} / \mathrm{dl}, 20 \%$; not significant). Moreover, a cortisol serum value in the normal range predicts a recurrence in only $\sim 17-31 \%$ [38].

According to the above, postoperative cortisol serum level alone is not an ideal marker of cure of $\mathrm{CD}$ and although the most important, it should be interpreted with other tests.

\section{Morning plasma ACTH}

There is no sufficient data about the predictive value of postsurgical plasma ACTH levels for the disease remission. The Invitti et al. analysis on 288 adults has reported that only half of patients with clinical remission showed decreased plasma ACTH levels [39]. Contrary to the results in adults, in the retrospective study by Batista et al. (72 children with $\mathrm{CD}$ ) children who remained in remission had significantly lower morning ACTH (and also cortisol levels) after TSS compared with those who relapsed $(P<0.001)$ [36].

\section{Urinary free cortisol}

Urinary free cortisol (UFC) alone cannot be a measure of post-TSS remission, however, several UFCs levels below the normal range with concurrent evidence of disease remission in other tests can be useful to confirm disease cure [40]. Most studies in adults show long-term remission if postoperative UFC concentrations are $<28-56 \mathrm{nmol} /$ day $(<10-20 \mu \mathrm{g} /$ day) $[2,19,21]$.

Studies on pediatric population show different results. In the Batista et al. study mentioned above, decreased UFC excretion after TSS was documented in all patients, including 4 patients with subsequent relapse of the disease, which confirms that UFC cannot be a predictive factor of long-term remission [36].

\section{Dexamethasone suppression test}

Some authors tried to use LDDST as a predictor of remission (studies in mixed groups consisted of children and adults) but because of the use of different dosages and no agreement of the serum cortisol cut-off value this test is not used widely to establish the cure of CD [41-43]. LDDST as a predictive factor for remission in children only has not been tested.

\section{CRH stimulation test}

Research in adults on the usefulness of CRH (corticotropine) test performed after TSS as a predictor of long-term remission was not conclusive. Avgerinos et al. analysis [44] has shown that there was no relapse in 23 adult patients who had a decreased response to CRH test performed after TSS (follow-up period 6-42 months after TSS). On the other hand, 3 patients (from 6 in this study), who had a normal response in the test, relapsed [44]. Lindsay et al. measured the response to oCRH (ovine $\mathrm{CRH}$ ) in 331 children and adults (age at TSS $36 \pm 0.8$ yrs, range 5-71, follow-up 10.6 yrs) [37]. oCRH-stimulated cortisol $(P<0.002)$ and ACTH $(P<0.04)$ values were higher for the recurrence than the remission group. However, no basal or stimulated ACTH or serum or urine cortisol cutoff value predicted all who later recurred.

Contrary to the results of studies in adults/adults\&children, in a study by Batista et al. (72 children, follow-up 24-120 months) a normal response to oCRH post-TSS was the predictive factor of nonremission [36].

Interestingly, Asuzu et al. used CRH stimulation test results to create new values named NEPVs (Normalized Early Postoperative Values) to improve prediction of nonremission [45]. NEPVs for cortisol and ACTH (calculated as immediate postoperative cortisol or ACTH levels minus preoperative post-CRH-stimulation test levels) predicted both early (10 days after TSS) and medium-term (11 months after TSS) nonremission (a group of adults\&children) [45]. AUROC (area under the receiver operating characteristic curve) for NEPV of cortisol was 0.78 (95\% CI: 0.61, 0.95); for NEPV of ACTH, it was 0.80 (95\% CI: $0.61,0.98$ ), so these new values can be helpful in predicting nonremission after TSS for CD [45].

\section{Desmopressin stimulation test}

In the early period after TSS, desmopressin (DDAVP) may stimulate ACTH secretion in the remnant corticotroph tumor (which have V3 receptors on their surface), but not in 
nontumor suppressed cells [46]. This fact can be used in the postoperative evaluation of cure. If the tumor is removed radically, ACTH and cortisol response to DDAVP disappears. Because, only $70-90 \%$ of patients with CD show an increase of ACTH and cortisol after DDAVP administration, the DDAVP test may be used only in patients with a positive response before surgery [47]. Furthermore, the Endocrine Society recommends its use as a part of research studies [48].

The results of two studies in adults/children \& adults $[49,50]$ show usefulness of the desmopressin test in predicting CD recurrence. M. Losa et al. (the study on 107 adult patients) indicate that, during follow-up monitoring, three patients, who had persistence of the ACTH response to desmopressin, relapsed 24-54 months after TSS [49]. Barbetta et al. (the study on 68 patients aged 13-70 yrs) show that 3 patients (from 13 who relapsed) had positive responses to desmopressin which preceded the remissionthey conclude that the positive responsiveness to desmopressin may be a criterion of risk for recurrence in patients who only normalized cortisol levels after surgery [50]. Unfortunately, there is no sufficient data on the usefulness of desmopressin test in children for prediction of $\mathrm{CD}$ relapse.

\section{Imaging}

A study by Ciric et al. has shown that detection of adenoma in magnetic resonance imaging (MRI) is associated with a greater chance of tumor localization at surgery, and also gives a better prognosis for immediate postsurgical remission [51]. The remission rate after TSS (defined as undetectable serum cortisol in the immediate postoperative period $<1.8 \mu \mathrm{g} / \mathrm{dL}$ ) is reported from 45 to $95 \%$ [4-9]. Some data has shown that there are other factors decreasing immediate and long-term remission rates, such as: macroadenoma, dural or cavernous sinus invasion, postoperative eucortisolism (in the absence of preoperative or postoperative medical treatment) and absence of tumor on MRI or ACTH positive tumor in pathology $[2,52]$.

Because the size of pituitary adenomas detected in MRI in children is usually less than $6 \mathrm{~mm}$ and their visualization rate is relatively poor due to the limited spatial resolution of MRI [6], there was a necessity of creating better imaging techniques. Spoiled gradient-recalled acquisition in the steady-state (SPGR) with improved spatial resolution is considered better than the conventional T-1 weighted spin echo (SE) technique in identifying pituitary tumors. The sensitivity of SPGR in detecting microadenomas is $80 \%$ in adults (vs sensitivity of $\mathrm{T} 1$ spin echo imaging 49\%) and $68 \%$ in children (vs. sensitivity of $\mathrm{T} 1$ spin echo imaging $29 \%$ ) [53, 54]. Comparably, detection of microadenomas is improved by demonstrating microadenomas as hypoenhancing regions using volumetric gradient recalled echo (3D-GRE) [53, 55]. Using the fact that contrast may be retained longer in pituitary adenomas compared with normal pituitary gland, delayed postcontrast FLAIR (fluid attenuated inversion recovery) imaging may have utility in identifying delayed contrast retention in pituitary adenomas $[56,57]$. The Chatain et al. study suggests that delayed microadenoma contrast washout may be detected as FLAIR hyperintensity in otherwise MRI-negative CD cases [58]. The authors of this study propose adding postcontrast FLAIR sequences to complement 3D-GRE for surgical planning in patients with CD [58]. Different technique18F-FDG PET/CT, is not recommended to diagnose CD. Feng et al. reported that the sensitivity of 18F-FDG PET was $67 \%$ and even lower for patients after treatment, based on analyzed $43 \mathrm{CD}$ patients [59]. Zhoua et al. in their study proved that $18 \mathrm{~F}-\mathrm{FDG}$ PET/CT plays a role in localizing the site for ectopic ACTH-dependent syndromes, although it plays a limited role in $\mathrm{CD}$ [60].

\section{Predictors of recurrence}

Although many researchers tried to find predictors for CD relapse, the results differ upon the study and, unfortunately, there is no universal prognostic factor that would be confirmed in all studies. Factors that can be associated with the increased risk of $\mathrm{CD}$ recurrence in adults and in children are presented in Table 1.

Several studies on adults assessing the usefulness of oCRH test in predicting $\mathrm{CD}$ recurrence have shown that the relapsing patients had higher cortisol or ACTH responses to oCRH than patients who stayed in remission [44, 61-64]. In the Alwani et al. study on 79 adults the absolute peak cortisol concentration after oCRH test gave the best diagnostic accuracy in predicting outcome of cortisol cutoff value of $600 \mathrm{nmol} / \mathrm{l}$ ) [62]. Baseline plasma ACTH levels and peak cortisol responses to oCRH were the best parameters for predicting relapse after TSS in the Invitti et al. study [63]. This study confirmed the usefulness of post-TSS CRH testing, because recurrence developed only in patients presenting a response of both hormones to $\mathrm{CRH}$ stimulation [63]. Comparably, in Lindsay et al. study mean basal and stimulated ACTH and stimulated cortisol values were significantly lower for patients in long-term remission compared with those who later recurred $(p<0.007-0.02)$ [37].

In the Alexandraki et al. study of 131 adults with $C D$ the time of hypothalamic-pituitary-adrenal axis (HPAA) recovery was the only prognostic factor for $\mathrm{CD}$ recurrence [28]. Chun-Heng Kuo et al. (a group of 52 adults) have shown that ACTH level before treatment had the positive correlation with the recurrence of the disease [65]. 
Table 1 Predictors of CD recurrence in adults and children

\begin{tabular}{|c|c|}
\hline Predictors of recurrence in adults & Predictors of recurrence in children \\
\hline \multicolumn{2}{|l|}{ - male gender } \\
\hline - younger age at diagnosis & - older age at the time of disease symptoms \\
\hline - longer duration of symptoms & - younger age at the time of surgery \\
\hline \multicolumn{2}{|l|}{ - severe clinical presentation } \\
\hline \multicolumn{2}{|l|}{ - depression or behavioral symptoms } \\
\hline \multicolumn{2}{|l|}{$\begin{array}{l}\text { - significantly elevated serum cortisol and UFC levels } \\
\text { preoperatively }\end{array}$} \\
\hline \multicolumn{2}{|c|}{ - higher postoperative basal and oCRH-stimulated cortisol/ACTH levels ${ }^{\mathrm{a}}$} \\
\hline \multicolumn{2}{|l|}{ - no evidence of adenoma in MRI } \\
\hline \multicolumn{2}{|c|}{ - no tumor identification at surgical intervention } \\
\hline \multicolumn{2}{|c|}{ - no tumor identification at post-surgical pathological examination } \\
\hline - large macroadenomas (tumor diameter $\geq 2,0 \mathrm{~cm}$ ) & - larger tumor diameter \\
\hline \multicolumn{2}{|c|}{$\begin{array}{l}\text { - tumor extension, especially to the suprasellar region and } \\
\text { with the involvement of the pituitary intermediate lobe }\end{array}$} \\
\hline \multicolumn{2}{|c|}{ - dural invasion or petrosal sinus invasion } \\
\hline \multicolumn{2}{|c|}{ - an early recovery of HPAA after TSS } \\
\hline \multicolumn{2}{|c|}{ - no histopathological confirmation of the pituitary corticotroph adenoma } \\
\hline \multicolumn{2}{|l|}{ - the absence of peritumoral Crooke's cells } \\
\hline & $\begin{array}{l}\text { - mutations in USP8 gene in resected tumor } \\
\text { tissue }^{\mathrm{a}}\end{array}$ \\
\hline$[28,29,33,41,42,52,61-65,69,70,112-121]$ & {$[7,8,30,36,61,66,67,114]$} \\
\hline
\end{tabular}

aexplanation in the text
As CD is rare in childhood, there is very limited data (in comparison to data on adult patients) with extended followup reporting prognostic factors of the disease recurrence in this population. The analysis by Lonser et al. of 200 children with $\mathrm{CD}$ (mean postoperative follow-up $6.8 \pm 4.7 \mathrm{yrs}$, range 0.3-21.3) has shown the following prognostic factors of $\mathrm{CD}$ recurrence: dural invasion or petrosal sinus invasion, older age at the time of disease symptoms (in contrast to younger in adults), no identification of adenoma during surgery and larger tumor diameter [8]. In the analysis by Devoe et al. of 42 children (mean follow-up $7.2 \mathrm{yrs}$, range 1.5-13.6) with CD recurrence of the disease was correlated with a younger age at the time of surgery [7]. Lodish et al. [30] have shown that an early recovery of HPAA after TSS may indicate disease recurrence (57 children, follow-up 6-36 months). A study by Batista et al. (72 children, followup 24-120 months) has shown the following factors associated with relapse: lack of histological confirmation of an adenoma, higher post-TSS serum cortisol or ACTH levels, a higher ACTH and cortisol responses to oCRH (CRH test performed after TSS), and glucocorticoid replacement for less than 6 months after surgery [36]. Also post-TSS morning cortisol and ACTH value mentioned above as predictors of long-term remission can be helpful in predicting recurrence of the disease.

Recent studies, both on pediatric (Faucz et al.; 42 children) and adult population (Albani et al.; 48 adults), indicate that recurrences appear to be more frequent in patients with USP8 mutant corticotroph tumors [66, 67]. However, these results are in contrast to the previous reports in adults (Hayashi et al., 60 adults) suggested that the USP8 mutated tumors are not as aggressive and that the long-term remission rates in patients with detected USP8 mutation are higher [68].

The recurrence rates are reported in 6-27\% children after initial remission $[4,8,36]$ and these results differ from the recurrence rates in adults who more often relapse-3 to 47\% [37, 48, 69]. CD recurrence was documented even after 15 years of successful surgery (in adult patient) [28], hence long-term follow-up of patients after TSS is crucial. In contrast to presented above data about lower recurrence rates in children, results of Leinung et al. study indicate that children and adolescents with $\mathrm{CD}$ are at greater risk of relapse than adults [4].

\section{Treatment in case of the disease recurrence or lack of remission}

The options of treatment for patients who do not achieve remission after TSS are: second pituitary surgery, pituitary radiotherapy, long-term medical therapy to control hypercortisolemia and bilateral adrenalectomy (BA) detailed below. In subjects with uncured/recurrent $\mathrm{CD}$, treatment options must be individualized. 


\section{Second pituitary surgery}

Second pituitary surgery is a good option when residual tumor is well visualized in MRI or has regrown but is not invasive $[2,19,21]$. Resection success rates (in adults) are lower in comparison to the first TSS (50-73\% vs 81\%) [70].

\section{Pituitary radiotherapy}

Pituitary radiotherapy is a good first-line treatment when the surgery cannot be performed or a second-line approach in the case of persistent disease/recurrence after surgery, especially when the tumor is invasive [2, 19, 21]. Conventional fractionated external beam radiotherapy delivers dosage of $4500-5000 \mathrm{cGy}$ total, and is usually given in 180-200 rad fractions over a period of 6 weeks [20]. Intensity-modulated radiotherapy (IMRT) enables dose adjustment for tumor contours and spares nearby crucial structures. There are newer forms of RT available now: stereotactic RT, photon knife (computer-assisted linear accelerator) and the gamma knife (cobalt-60).

From available literature (Table 2), mean time to cure in adults is $1.5-5$ years $[71,72]$ and the cure rates of conventional fractionated RT are 56-83\% [71, 72]. Despite the published data of the results in children are limited, available date provide that the mean time to cure in children is shorter: $0.75-2.86$ years and that the cure rates are higher in comparison to adults-50-100\% [5, 10, 73-75]. According to studies in adults (by Schteingart) and children (by Jennings), there are some promising results of a combined pituitary RT and mitotane, which improves the success rate of either modality given alone curing $\sim 66 \%$ patients $[74,76]$.

The outcome of pituitary irradiation in CD has been reported in a number of small studies that focus mainly on adult population. Hypopituitarism is the most common adverse effect of RT, more frequent if TSS is performed before RT [24]. The other adverse effects of RT (visual impairment, radiation oncogenesis) are very rare [77, 78]. Estrada et al. in his analysis of 30 adult patients with persistent or recurrent $\mathrm{CD}$ have shown that $57 \%$ of patients (17/30) had GHD after RT (GHD was diagnosed if plasma growth values were $<15 \mathrm{mIU} / \mathrm{L}$ after the inducement of hypoglycemia), 33\% (10/30) had gonadotropin deficiency, $13 \%(4 / 30)$ had a deficiency of thyrotropin, and 3\% (1/30) had a deficiency of corticotropin [77]. 83\% had remissions during a median follow-up of 42 months (range: 18-114). The remissions began 6-60 months after RT, but in most cases $(73 \%)$ remission occurred during the first 2 years. None of the patients had a relapse of CD after remission was achieved [79].

Results from studies performed on pediatric population present that in children after RT pituitary deficiencies do not

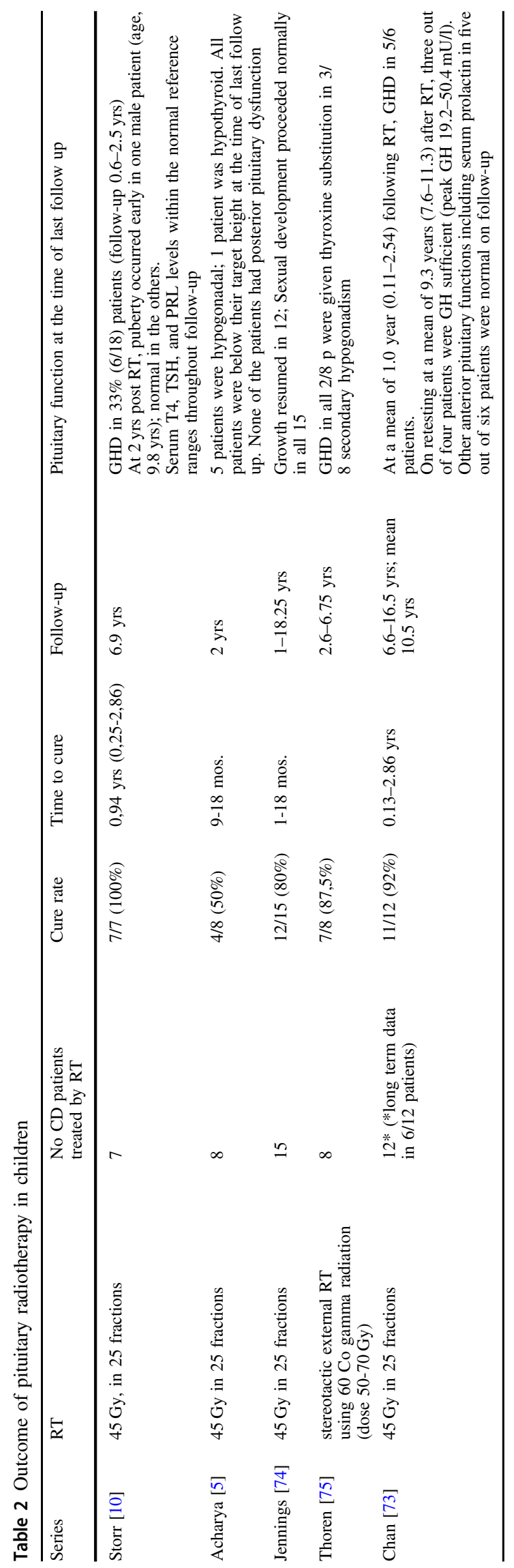


occur so often. Storr et al. described the efficacy of RT in 7 children treated by pituitary RT post-TSS [10]. GH secretion was assessed at $0.6-2.5$ yrs post RT in all patients: $33 \%$ $(6 / 18)$ of patients had GHD (GHD was defined as peak GH $<20 \mathrm{mIU} / \mathrm{L}$ ). At 2 yrs post RT, puberty occurred early in one male patient (age 9.8 yrs) but was normal in the others [10]. Serum T4, TSH, and PRL levels remained within the normal reference ranges throughout mean 6.9 yrs follow-up. Similarly, Chan et al. reported in their retrospective analysis the results of anterior pituitary function in 6 patients treated with pituitary RT after $>6$ yrs follow-up [73]. Despite the fact that at a mean of 1.0 year (0.11-2.54) following RT, GHD was present in $83 \%$ patients (GHD in childhood was defined as peak $\mathrm{GH}$ on provocation testing $<20 \mathrm{mIU} / \mathrm{L}$; severe GHD in pediatric and adult patients was defined as peak $\mathrm{GH}$ level $<9 \mathrm{mIU} / \mathrm{l})$, on retesting at a mean of $9.3 \mathrm{yrs}$ (7.6-11.3) after RT 75\% patients were GH sufficient. Other anterior pituitary functions including serum PRL in 5/6 patients were normal on follow-up [73].

\section{Pharmacotherapy}

Definitive treatment such as TSS (and RT in the case off TSS failure), rather than pharmacotherapy, is currently recommended for the management of pediatric CD. Drug therapies for children with $\mathrm{CD}$ are limited and not well studied. They can be applied to urgently lower cortisol level in patients with severe hypercortisolemia in preparation for surgery or whilst awaiting the effects of RT [10]. Long-term treatment may not be effective because of oversecretion of corticotrophin [2].

There are several drugs that can be used: Ketoconazole and other adrenal enzyme inhibitors: metyrapone, aminoglutethimide and trilostane may be used alone or in combinations to control hypercortisolism but they do not destroy adrenocortical cells that secrete cortisol [20]. None of these drugs is approved by the FDA (US Food and Drug Administration) for CD treatment [80]. Ketoconazole is an agent that affects many P450 enzymes (depending on the dose used) blocking adrenal steroidogenesis. Ketoconazole therapy requires liver function monitoring [81]. The dose is 300 to $1200 \mathrm{mg} /$ day $[81,82]$ and $45-50 \%$ of patients show long-term control with continued use [81]. Ketoconazole has not been approved by the FDA for CD treatment neither in children nor in adults [80], because of the risk of severe liver injury and harmful interactions with other medications [80]. The European Agency EMA had recommended a permission of a marketing authorization for $\mathrm{KCN}$ (HRA Pharma) in the treatment of CS [83]. Metyrapone increases cortisol metabolites in the serum and urine due to the predominant inhibition of 11-hydroxylase (also the other steroidogenesis enzymes but to a lesser extent) [84]. Metyrapone has been used safely in children awaiting for
$\mathrm{RT}$ results [10], the recommended dosage is $750-2250 \mathrm{mg} /$ day [81]. Metyrapone is approved for the treatment of CS in the European Union in adults. Mitotane decreases cortisol by direct inhibition of steroidogenesis at a few enzymatic steps [85]. It also destroys adrenocortical cells secreting cortisol. Therapy with mitotane alone can be successful in up to $72 \%$ of patients with CD [86]. Mitotane (3 mg/day) can be used also as an additional drug with metyrapone [10]. Aminoglutethimide blocks the conversion of cholesterol to pregnenolone in the adrenal cortex, inhibiting the synthesis of cortisol, aldosterone, and androgens. Aminoglutethimide can be used in a combine therapy with metyrapone (the dosage is $1 \mathrm{~g} /$ day) [10]. Trilostane inhibits the conversion of pregnenolone to progesterone. Storr et al. described in their study successful use of oral drugs (ketoconazole, metyrapone, aminoglutethimide or mitotane) to control hypercortisolemia in 8 patients after pituitary RT [10].

Another pharmaceutical drug-etomidate has been occasionally used in the treatment of CD [87, 88]. Greening et al. described a 6.2-year-old male patient with severe hypercortisolemia and life-threatening complications (respiratory failure, severe psychosis) of CD in whom the therapy with metyrapone and ketoconazole was ineffective. Intravenous administration of etomidate had successfully lowered the cortisol level before bilateral adrenalectomy was done [88].

There are also newer therapies for patients unsuccessfully treated by surgery that directly affect the pituitary tumor: cabergoline and pasireotide [89, 90]. Cabergoline is a dopamine agonist and its role in CD treatment has been debated. Pivonello in his study [89] has shown that cabergoline treatment is effective in controlling cortisol secretion for at least $1-2$ yrs in more than $33 \%$ of a limited population of patients with CD (20 patients in the age 24-60 yrs with persistent CD after unsuccessful surgery). Currently, cabergoline is not approved by FDA for CD treatment.

Specific somatostatin analogs are promising in achieving CD therapeutic goals. Tumors corticotroph cells have on their surface somatostatin receptors (SSTR), mainly SSTR5 and SSTR2 [91-93]. The SSTR subtype 5 has become a therapeutic target in patients with $C D$ thanks to the use of the somatostatin analog-pasireotide that has the highest affinity for this receptor subtype [89, 90, 94]. Both subtypes: SSTR5 and SSTR2 have been shown to be involved in the regulation of ACTH release [86, 95]. Several studies (including large phase III clinical trial) have proven that pasireotide causes normalization of urinary cortisol in 25-30\% of CD adult patients [90, 93, 96, 97]. Pasireotide (Signifor) has been approved for adult CD treatment by the FDA and the European Commission [80]. The use of pasireotide in children is limited to single cases and there are no studies summarizing the effects of treatment in this 
group of patients. Yordanova et al. describes 1 female patient diagnosed with $\mathrm{CD}$ at the age of $13.8 \mathrm{yrs}$, who had relapse of CD 6 years after TSS [25]. The patient refused BA and was being managed with pasireotide with good control of hypercortisolemia.

Recently, mifepristone (a progesterone receptor antagonist with glucocorticoid receptor antagonist activity at higher doses) was approved by FDA for treatment of adults with CS to control hyperglycemia [98]. Improvement in clinical, metabolic, and psychosocial outcome in adults has been documented [97]. Data on the use of medical therapies to treat CS in children and adolescents are limited [99]. At present, mifepristone is the promising option for long-term medical treatment of refractory CD in children. Unfortunately the clinical trial "Mifepristone in children with refractory Cushing's disease", which was to be the largest study on the effects of mifepristone in children gave no results because of lack of patients enrollment.

\section{Bilateral adrenalectomy}

Bilateral adrenalectomy is the treatment option for CD patients who have either failed surgery or RT or where TSS is not possible or available. If performed properly, BA provides immediate relief from hypercortisolism. A laparoscopic approach is the preferred method as is associated with reduced morbidity. There are some disadvantages of BA for the patients: 1. a necessity of lifelong replacement with glucocorticoids and mineralocorticoids; 2 . BA does not eliminate the cause underlying the hypersecretion of $\mathrm{ACTH} ; 3$. the perioperative mortality is approximately 3 times higher than that of TSS (3\% vs. 1\% in TSS); 4. recurrences can (rarely) occur (as the result of the growth of adrenal rest tissues) [20]; 5. the risk of Nelson's syndrome (NS) - an important complication of BA when the patient develops macroadenomas that secrete ACTH [100].

NS was documented months or years in up to $15 \%$ of children with CD after BA [20,24]. NS appears to be more frequent in children than in adults (an incidence of 8-43\% in adults [101] and 25-75\% in children [102-104] and often requires pituitary surgery or RT [105]. Children after BA seem to have higher risk of NS in comparison to adults-for this reason they should be carefully monitored-they require annual monitoring with MRI and assessment of plasma ACTH values [102-104].

\section{Quality of life}

Numerous studies assessing the quality of life in patients after CD treatment have been published, but they mainly concern adults [106, 107]. Available data had shown that adult CD patients still experience significant problems in many areas of life, even if they achieved biochemical remission and are many years after definitive treatment. CDinduced hypercortisolemia, even cured, may have long-term adverse effects affecting mood and functioning in society [106]. Van Aken in his analysis of 58 adults after an average of 13.4 yrs of follow-up underlines that patients general QoL is decreased, with mainly weakened psychosocial and physical spheres, especially in those with hypopituitarism [107]. It has also been proven that CD patients have impaired psychological well-being and psychosocial functioning compared to patients with other pituitary tumors [106, 108-110].

Similar conclusions are provided by the only prospective study by Keil et al. conducted on pediatric population [111]. The study (40 children with CS including 34 children with CD) documented that pediatric CS is associated with impaired HRQL one-year after cure [111]. Post-TSS scores of all CS patients remained significantly below US normative data for: physical function $(P<0.02)$, role-physical $(P<0.02)$, global health perception $(P<0.001)$, emotional impact (parent) $(P<0.001)$ and physical summary score $(P$ $<0.001)$ [111]. The findings of these studies demonstrate that children and adolescents affected by CS have impaired QoL, which only partially resolves after successful treatment.

\section{Compliance with ethical standards}

Conflict of interest The authors declare that they have no conflict of interest.

Publisher's note: Springer Nature remains neutral with regard to jurisdictional claims in published maps and institutional affiliations.

Open Access This article is distributed under the terms of the Creative Commons Attribution 4.0 International License (http://crea tivecommons.org/licenses/by/4.0/), which permits unrestricted use, distribution, and reproduction in any medium, provided you give appropriate credit to the original author(s) and the source, provide a link to the Creative Commons license, and indicate if changes were made.

\section{References}

1. R. Pivonello, M. De Leo, A. Cozzolino, A. Colao, The Treatment of Cushing's Disease. Endocrine Review 36(4), 385-486 (2015). https://doi.org/10.1210/er.2013-1048

2. B.M. Biller, A.B. Grossman, P.M. Stewart, S. Melmed, X. Bertagna, J. Bertherat, Treatment of adrenocorticotropindependent Cushing's syndrome: a consensus statement. Journal of Clinical Endocrinology and Metabolism 93, 2454-2462 (2008)

3. L.K. Nieman, B.M. Biller, J.W. Findling, M.H. Murad, J. Newell-Price, M.O. Savage, Treatment of cushing's syndrome: an endocrine society clinical practice guideline. Journal of 
Clinical Endocrinology and Metabolism 100(8), 2807-2831 (2015)

4. M.C. Leinung, L.A. Kane, B.W. Scheithauer, P.C. Carpenter, E. R. Laws Jr., D. Zimmerman, Long term follow-up of transsphenoidal surgery for the treatment of Cushing's disease in childhood. Journal of Clinical Endocrinology and Metabolism 80 (8), 2475-2479 (1995)

5. S.V. Acharya, R.A. Gopal, J. Goerge, P.S. Menon, T.R. Bandgar, N.S. Shah, Radiotherapy in paediatric Cushing's disease: efficacy and long term follow up of pituitary function. Pituitary 13(4), 293-297 (2010). https://doi.org/10.1007/s11102-0100231-x

6. H.L. Storr, M.O. Savage, Management of endocrine disease: paediatric Cushing's disease. European Journal of Endocrinology 173(1), 35-45 (2015). https://doi.org/10.1530/EJE-15-0013

7. D.J. Devoe, W.L. Miller, F.A. Conte, S.L. Kaplan, M.M. Grumbach, S.M. Rosenthal et al. Long-term outcome in children and adolescents after transsphenoidal surgery for Cushing's disease. Journal of Clinical Endocrinology and Metabolism 82 (10), 3196-3202 (1997)

8. R.R. Lonser, J.J. Wind, L.K. Nieman, R.J. Weil, H.L. DeVroom, E.H. Oldfield, Outcome of surgical treatment of 200 children with Cushing's disease. Journal of Clinical Endocrinology and Metabolism 98, 892-901 (2013). https://doi.org/10.1210/jc. 2012-3604

9. N.S. Shah, A. Lila, Childhood Cushing disease: a challenge in diagnosis and management. Hormone Research in Paediatrics 76 (Suppl 1), 65-70 (2011). https://doi.org/10.1159/000329173

10. H.L. Storr, P.N. Plowman, P.V. Carroll, I. Francois, G.E. Krassas, F. Afshar et al. Clinical and endocrine responses to pituitary radiotherapy in pediatric Cushing's disease: an effective second-line treatment. Journal of Clinical Endocrinology and Metabolism 88, 34-37 (2003)

11. A.S. Kanter, A.O. Diallo, J.A. Jane Jr., J.P. Sheehan, A.R. Asthagiri, R.J. Oskouian et al. Single-center experience with pediatric Cushing's disease. Journal of Neurosurgery 103, 413-420 (2005)

12. S.M. Joshi, R.J. Hewitt, H.L. Storr, K. Rezajooi, H. Ellamushi, A.B. Grossman, Cushing's disease in children and adolescents: 20 years of experience in a single neurosurgical center. Neurosurgery 57, 281-285 (2005). https://doi.org/10.1227/01.NEU. 0000166580.94215 .53

13. H.L. Storr, K.I. Alexandraki, L. Martin, A.M. Isidori, G.A. Kaltsas, J.P. Monson et al. Comparisons in the epidemiology, diagnostic features and cure rate by transsphenoidal surgery between paediatric and adult-onset Cushing's disease. European Journal of Endocrinology 164(5), 667-74 (2011). https://doi.org/ 10.1530/EJE-10-1120

14. J. Hardy, Transphenoidal microsurgery of the normal and pathological pituitary. Clinical Neurosurgery 16, 185-217 (1969)

15. I. Ciric, S. Rosenblatt, J.C. Zhao, Transsphenoidal microsurgery. Neurosurgery 51(1), 161-169 (2002)

16. P. Cappabianca, L.M. Cavallo, A. Colao, E. de Divitiis, Surgical complications associated with the endoscopic endonasal transsphenoidal approach for pituitary adenomas. Journal of Neurosurgery 97, 293-8 (2002)

17. H.L. Storr, W.M. Drake, J. Evanson, M. Matson, D.M. Berney, A.B. Grossman, S.A. Akker et al. Endonasal, endoscopic transsphenoidal pituitary surgery: early experience and outcome in paediaric Cushing's disease. Clinical Endocrinology 80, 270-278 (2014). https://doi.org/10.1111/cen.12275

18. R. Pivonello, M.C. De Martino, M. De Leo, G. Lombardi, A. Colao, Cushing's Syndrome. Endocrinology and Metabolism Clinics of North America 37, 135-149 (2008). https://doi.org/10. 1016/j.ecl.2007.10.010
19. J. Newell-Price, X. Bertagna, A.B. Grossman, L.K. Nieman, Cushing's syndrome. Lancet 367, 1605-1617 (2006). https://doi. org/10.1016/S0140-6736(06)68699-6

20. M.A. Magiakou, G.P. Chrousos, Cushing's syndrome in children and adolescents: current diagnostic and therapeutic strategies. Journal of Endocrinological Investigation 25(2), 181-94 (2002)

21. G. Arnaldi, A. Angeli, A.B. Atkinson, X. Bertagna, F. Cavagnini, G.P. Chrousos et al. Diagnosis and complications of Cushing's syndrome: a consensus statement. Journal of Clinical Endocrinology \& Metabolism 88, 5593-5602 (2003). https://doi. org/10.1210/jc.2003-030871

22. T.T. Chung, J. Evanson, D. Walker, S.A. Akker, G.M. Besser, J. P. Monson et al. Safety of GH replacement in hypopituitary patients with nonirradiated pituitary and peripituitary tumours. Clinical Endocrinology 68, 965-969 (2008). https://doi.org/10. 1111/j.1365-2265.2007.03135.x

23. A. Lacroix, R.A. Feelders, C.A. Stratakis, L.K. Nieman, Cushing's syndrome. Lancet 386, 913-927 (2015). https://doi.org/10. 1016/S0140-6736(14)61375-1

24. C.A. Stratakis, Cushing's syndrome in pediatrics. Endocrinology and Metabolism Clinics of North America 41(4), 793-803 (2012). https://doi.org/10.1016/j.ecl.2012.08.002

25. G. Yordanova, L. Martin, F. Afshar, I. Sabin, G. Alusi, N.P. Plowman et al. Long-term outcomes of children treated for Cushing's disease: a single center experience. Pituitary 19, 612-624 (2016). https://doi.org/10.1007/s11102-016-0756-8

26. M.A. Magiakou, G. Mastorakos, E.H. Oldfield, Cushing's syndrome in children and adolescents, presentation, diagnosis and therapy. The New England Journal of Medicine 331, 629-636 (1994). 10.1056

27. M. Berker, I. Işikay, D. Berker, M. Bayraktar, A. Gürlek, Early promising results for the endoscopic surgical treatment of Cushing's disease. Neurosurgical Review 37, 105-114 (2014). https://doi.org/10.1007/s10143-013-0506-6

28. K.I. Alexandraki, G.A. Kaltsas, A.M. Isidori, H.L. Storr, F. Afshar, I. Sabin et al. Long-term remission and recurrence rates in Cushing's disease: predictive factors in a single centre study. European Journal of Endocrinology 168, 639-648 (2013). https://doi.org/10.1530/EJE-12-0921

29. G. Aranda, J. Enseñat, M. Mora, M. Puig-Domingo, M.J. Martínez de Osaba, G. Casals, et al. Long-term remission and recurrence rate in a cohort of Cushing's disease: the need for long-term follow-up. Pituitary 18(1), 142-9 (2015). https://doi. org/10.1007/s11102-014-0567-8

30. M. Lodish, S.V. Dunn, N. Sinaii, M.F. Keil, C.A. Stratakis, Recovery of the hypothalamic-pituitary-adrenal axis in children and adolescents after surgical cure of Cushing's disease. Journal of Clinical Endocrinology and Metabolism 97, 1483-1491 (2012). https://doi.org/10.1210/jc.2011-2325

31. M.O. Savage, H.L. Storr, Pediatric Cushing's disease: management issues. Indian Journal of Endocrinology and Metabolism 16 (Suppl 2), S171-S175 (2012). https://doi.org/10.4103/22308210.104032

32. A.B. Atkinson, D.R. McCance, L. Kennedy, B. Sheridan, Cyclical Cushing's syndrome first diagnosed after pituitary surgery: a trap for the unwary. Clinical Endocrinology 36(3), 297-299 (1992)

33. L.S. Blevins Jr., J.H. Christy, M. Khajavi, G.T. Tindall, Outcomes of therapy for Cushing's disease due to adrenocorticotropin-secreting pituitary macroadenomas. Journal of Clinical Endocrinology and Metabolism 83, 63-67 (1998)

34. J.J. Acebes, J. Martino, C. Masuet, E. Montanya, J. Soler, Early post-operative ACTH and cortisol as predictors of remission in Cushing's disease. Acta Neurochirurgica 149, 471-479 (2007). https://doi.org/10.1007/s00701-007-1133-1 
35. P.J. Trainer, H.S. Lawrie, J. Verhelst, T.A. Howlett, D.G. Lowe, A.B. Grossman et al. Transsphenoidal resection in Cushing's disease: undetectable serum cortisol as the definition of successful treatment. Clinical Endocrinology 38, 73-78 (1993)

36. D.L. Batista, E.H. Oldfield, M.F. Keil, C.A. Stratakis, Postoperative testing to predict recurrent Cushing disease in children. Journal of Clinical Endocrinology and Metabolism 94(8), 2757-2765 (2009). https://doi.org/10.1210/jc.2009-0302

37. J.R. Lindsay, E.H. Oldfield, C.A. Stratakis, L.K. Nieman, The postoperative basal cortisol and CRH tests for prediction of longterm remission from Cushing's disease after transsphenoidal surgery. Journal of Clinical Endocrinology and Metabolism 96, 2057-2064 (2011). https://doi.org/10.1210/jc.2011-0456

38. M.E. Sughrue, J.K. Shah, J.K. Devin, S. Kunwar, L.S. Blevins Jr., Utility of the immediate postoperative cortisol concentrations in patients with Cushing's disease. Neurosurgery 67, 688-695 (2010). https://doi.org/10.1227/01.NEU.0000374722.50042.FF

39. C. Invitti, G. Redaelli, G. Baldi, F. Cavagnini, Glucocorticoid receptors in anorexia nervosa and Cushing's disease. Biological Psychiatry 45(11), 1467-1471 (1999)

40. J.M. Erfe, A. Perry, J. McClaskey, S.E. Inzucchi, W.S. James, T. Eid et al. Long-term outcomes of tissue-based ACTH-antibody assay-guided transsphenoidal resection of pituitary adenomas in Cushing disease. Journal of Neurosurgery 129, 629-641 (2018). https://doi.org/10.3171/2017.3.JNS162245

41. G.H. Chee, D.B. Mathias, R.A. James, P. Kendall-Taylor, Transsphenoidal pituitary surgery in Cushing's disease: can we predict outcome? Clinical Endocrinology 54(5), 617-26 (2001)

42. B.M. Hofmann, M. Hlavac, R. Martinez, M. Buchfelder, O.A. Müller, R. Fahlbusch, Long-term results after microsurgery for Cushing disease: experience with 426 primary operations over 35 years. Journal of Neurosurgery 108(1), 9-18 (2008). https:// doi.org/10.3171/JNS/2008/108/01/0009

43. D.R. McCance, D.S. Gordon, T.F. Fannin, D.R. Hadden, L. Kennedy., B. Sheridan et al. Assessment of endocrine function after transsphenoidal surgery for Cushing's disease. Clinical Endocrinology 38, 79-86 (1993)

44. P.C. Avgerinos, G.P. Chrousos, L.K. Nieman, E.H. Oldfield, D. L. Loriaux, G.B. Cutler Jr., The corticotropin-releasing hormone test in the postoperative evaluation of patients with cushing's syndrome. Journal of Clinical Endocrinology and Metabolism 65 (5), 906-913 (1987)

45. D. Asuzu, G.P. Chatain, C. Hayes, S. Benzo, R. McGlotten, M. Keil et al. Normalized early postoperative cortisol and ACTH values predict nonremission after surgery for cushing disease. Journal of Clinical Endocrinology and Metabolism 102(7), 2179-2187 (2017). https://doi.org/10.1210/jc.2016-3908

46. D.A. Vassiliadi, S. Tsagarakis, Diagnosis of endocrine disease: the role of the desmopressin test in the diagnosis and follow-up of Cushing's syndrome. European Journal of Endocrinology 178 (5), 201-214 (2018). https://doi.org/10.1530/EJE-18-0007

47. T. Suda, K. Kageyama, T. Nigawara, S. Sakihara, Evaluation of diagnostic tests for ACTH-dependent Cushing's syndrome. Endocrine Journal 56, 469-476 (2009). https://doi.org/10.1507/ endocrj.K08E-353

48. L.K. Nieman, B.M. Biller, J.W. Findling, J. Newell-Price, M.O. Savage, P.M. Stewart et al. The diagnosis of Cushing's syndrome: an Endocrine Society Clinical Practice Guideline. Journal of Clinical Endocrinology and Metabolism 93(5), 1526-1540 (2008). https://doi.org/10.1210/jc.2008-0125

49. M. Losa, P. Mortini, S. Dylgjeri, R. Barzaghi et al. Desmopressin stimulation test before and after pituitary surgery in patients with Cushing's disease. Clinical Endocrinology 55(1), 61-8 (2001)

50. L. Barbetta, C. Dall'Asta, G. Tomei, M. Locatelli et al. Assessment of cure and recurrence after pituitary surgery for
Cushing's disease. Acta Neurochirurgica 143(5), 477-481 (2001)

51. I. Ciric, J.C. Zhao, H. Du, J.W. Findling, M.E. Molitch, R.E. Weiss et al. Transsphenoidal surgery for Cushing disease: experience with 136 patients. Neurosurgery 70(1), 70-80 (2012). https://doi.org/10.1227/NEU.0b013e31822dda2c

52. R.D. Dickerman, E.H. Oldfield, Basis of persistent and recurrent Cushing disease: an analysis of findings at repeated pituitary surgery. Journal of Neurosurgery 97, 1343-1349 (2002). https:// doi.org/10.3171/jns.2002.97.6.1343

53. N. Patronas, N. Bulakbasi, C.A. Stratakis, A. Lafferty, E.H. Oldfield, J. Doppman et al. Spoiled gradient recalled acquisition in the steady state technique is superior to conventional postcontrast spin echo technique for magnetic resonance imaging detection of adrenocorticotropin-secreting pituitary tumors. Journal of Clinical Endocrinology and Metabolism 88, 1565-1569 (2003)

54. D. Batista, N.A. Courkoutsakis, E.H. Oldfield et al. Detection of adrenocorticotropin-secreting pituitary adenomas by magnetic resonance imaging in children and adolescents with Cushing disease. Journal of Clinical Endocrinology and Metabolism 90, 5134-5140 (2005)

55. G.U. Mehta, B.K. Montgomery, P. Raghavan, S. Sharma, L.K. Nieman, N. Patronas et al. Different imaging characteristics of concurrent pituitary adenomas in a patient with Cushing's disease. Journal of Clinical Neuroscience 22, 891-894 (2015)

56. A.J. Dwyer, J.A. Frank, J.L. Doppman, E.H. Oldfield, A.M. Hickey, G.B. Cutler et al. Pituitary adenomas in patients with Cushing disease: initial experience with Gd-DTPA-enhanced MR imaging. Radiology 163, 421-426 (1987)

57. W. Kucharczyk, D.O. Davis, W.M. Kelly, G. Sze, D. Norman, T. H. Newton, Pituitary adenomas: high-resolution MR imaging at 1.5 T. Radiology 161, 761-765 (1986)

58. G.P. Chatain, N. Patronas, J.G. Smirniotopoulos, M. Piazza, Potential utility of FLAIR in MRI-negative Cushing's disease. Journal of Neurosurgery 129(3), 620-628 (2018). https://doi.org/ 10.3171/2017.4.JNS17234.

59. Z. Feng, D. He, Z. Mao, Z. Wang, Y. Zhu, X. Zhang et al. Utility of 11C-methionine and 18F-FDG PET/CT in patients with functioning pituitary adenomas. Clinical Nuclear Medicine 41, 130-134 (2016)

60. J. Zhoua, H. Jua, L. Zhua, Y. Pana, J. Lvb, Y. Zhang, Value of fluorine-18-fluorodeoxyglucose PET/CT in localizing the primary lesion in adrenocorticotropic hormone-dependent Cushing syndrome. Nuclear Medicine Communications 40(5), 539-544 (2019). https://doi.org/10.1097/MNM.0000000000000989

61. G.F. Pieters, A.R. Hermus, E. Meijer, A.G. Smals, P.W. Kloppenborg, Predictive factors for initial cure and relapse rate after pituitary surgery for Cushing's disease. Journal of Clinical Endocrinology and Metabolism 69, 1122-1126 (1989)

62. R.A. Alwani, W.W. de Herder, M.O. van Aken, J.H. van den Berge, E.J. Delwel, A.H.G. Dallenga et al. Biochemical predictors of outcome of pituitary surgery for Cushing's disease. Neuroendocrinology 91, 169-178 (2010). https://doi.org/10. $1159 / 000258677$

63. C. Invitti, F. Pecori Giraldi, M. De Martin, F. Cavagnini, Diagnosis and management of Cushing's syndrome: results of an Italian multicentre study. Study Group of the Italian Society of Endocrinology on the Pathophysiology of the HypothalamicPituitary-Adrenal Axis. Journal of Clinical Endocrinology and Metabolism 84, 440-448 (1999)

64. F. Vignati, M.E. Berselli, P. Loi, Early postoperative evaluation in patients with Cushing's disease: usefulness of ovine corticotropinreleasing hormone test in the prediction of recurrence of disease. European Journal of Endocrinology 130, 235-241 (1994) 
65. Chun-Heng, K., Shyang-Rong S., Hung-Yuan, L., Szu-Chi, C., Po-Ju, H., Fen-Yu, T.: Adrenocorticotropic hormone levels before treatment predict recurrence of Cushing's disease. J. Form. Med. Assoc. 116, 441-447. https://doi.org/10.1016/j.jfma. 2016.08.008

66. A. Albani, L.G. Pérez-Rivas, C. Dimopoulou, S. Zopp, P. ColónBolea, S. Roeber, et al. The USP8 mutational status may predict long-term remission in patients with Cushing's disease. Clin. Endocrinol. [Epub ahead of print], https://doi.org/10.1111/cen. 13802

67. F.R. Faucz, A. Tirosh, C. Tatsi, Somatic USP8 gene mutations are a common cause of pediatric cushing disease. Journal of Clinical Endocrinology and Metabolism 102(8), 2836-2843 (2017)

68. K. Hayashi, N. Inoshita, K. Kawaguchi, A. Ibrahim Ardisasmita, H. Suzuki, N. Fukuhara et al. The USP8 mutational status may predict drug susceptibility in corticotroph adenomas of Cushing's disease. European Journal of Endocrinology 174(2), 213-26 (2016). https://doi.org/10.1530/EJE-15-0689

69. G.D. Hammer, J.B. Tyrell, K.R. Lamborn, C.B. Applebury, E.T. Hannegan, S. Bell et al. Transsphenoidal microsurgery for Cushing's disease: initial outcome and long-term results. Journal of Clinical Endocrinology and Metabolism 89(12), 6348-6357 (2004). https://doi.org/10.1210/jc.2003-032180

70. Z. Ram, L.K. Nieman, G.B. Cutler Jr., Early repeat surgery for persistent Cushing's disease. Journal of Neurosurgery 80(1), 37-45 (1994)

71. D. Zierhut, M. Flentje, J. Adolph, J. Erdmann, F. Raue, M. Wannenmacher, External radiotherapy of pituitary adenomas. International Journal of Radiation Oncology Biology Physics 33 (2), 307-314 (1995)

72. J. Estrada, J. García-Uría, C. Lamas, J. Alfaro, T. Lucas, S. Diez et al. The complete normalization of the adrenocortical function as the criterion of cure after transsphenoidal surgery for Cushing's disease. Journal of Clinical Endocrinology and Metabolism 86, 5695-5699 (2001). https://doi.org/10.1210/jcem.86.12. 8069

73. L.F. Chan, H.L. Storr, P.N. Plowman, L.A. Perry, G.M. Besser, A.B. Grossman et al. Long-term anterior pituitary function in patients with paediatric Cushing's disease treated with pituitary radiotherapy. European Journal of Endocrinology 156(4), 477-82 (2007). https://doi.org/10.1530/EJE-06-0588

74. A.S. Jennings, G.W. Liddle, D.N. Orth, Results of treating childhood Cushing's disease with pituitary irradiation. New England Journal of Medicine 297, 957-962 (1977)

75. M. Thoren, T. Rahn, B. Hallengren, P.H. Kaad, K.O. Nilsson, H. Ravn et al. Treatment of Cushing's disease in childhood and adolescence by stereotactic pituitary irradiation. Acta Paediatrica Scandinavica 75, 388-395 (1986)

76. D.E. Schteingart, H.S. Tsao, C.I. Taylor, A. McKenzie, R. Victoria, B.A. Therrien, Sustained remission of Cushing's disease with mitotane and pitutiary irradiation. Annals of Internal Medicine 92, 613-619 (1980). https://doi.org/10.7326/00034819-92-5-613

77. P.N. Plowman. Pituitary radiotherapy: techniques and potential complications. Clinical Endocrine Oncology. R. Sheaves, P.J. Jenkins, J.A. Wass (eds) Blackwell Scientific Publications, Oxford), 1997) 185-188

78. P.N. Plowman, Pituitary adenoma radiotherapy-when, who and how? Clinical Endocrinology 51, 265-271 (1999)

79. J. Estrada, M. Boronat, M. Mielgo, R. Magallón, I. Millan, S. Díez et al. The long-term outcome of pituitary irradiation after unsuccessful transsphenoidal surgery in Cushing's disease. New England Journal of Medicine 336(3), 172-177 (1997)

80. M. Fleseriu, F. Castinetti, Updates on the role of adrenal steroidogenesis inhibitors in Cushing's syndrome: a focus on novel therapies. Pituitary 19(6), 643-653 (2016). https://doi.org/10. 1007/s11102-016-0742-1

81. F. Castinetti, I. Morange, P. Jaquet, B. Conte-Devolx, T. Brue, Ketoconazole revisited: a preoperative or postoperative treatment in Cushing's disease. European Journal of Endocrinology 158 (1), 91-99 (2008). https://doi.org/10.1530/EJE-07-0514

82. M.O. Savage, A. Lienhardt, M.C. Lebrethon, L.B. Johnston, A. Huebner., A.B. Grossman et al. Cushing's disease in childhood: presentation, investigation, treatment and long-term outcome. Hormone Research 55(Suppl 1), 24-30 (2001). https://doi.org/ 10.1159/000063459

83. M. Fuertes, J. Tkatch, J. Rosmino, L. Nieto, M.A. Guitelman, E. Artz, New insights in cushing disease treatment with focus on a derivative of vitamin A. Frontiers in Endocrinology 9, 262 (2018)

84. E. Daniel, S. Aylwin, O. Mustafa, S. Ball, A. Munir, K. Boelaert et al. Effectiveness of metyrapone in treating Cushing's syndrome: a retrospective multicenter study in 195 patients. Journal of Clinical Endocrinology and Metabolism 100(11), 4146-4154 (2015). https://doi.org/10.1210/jc.2015-2616

85. L. Ghataore, I. Chakraborti, S.J. Aylwin, K.M. Schulte, D. Dworakowska, P. Coskeran, Effects of mitotane treatment on human steroid metabolism: implications for patient management. Endocrine Connections 1(1), 37-47 (2012). https://doi.org/10. 1530/EC-12-0028

86. C. Baudry, J. Coste, R. Bou Khalil, S. Silvera, L. Guignat, J. Guibourdenche et al. Efficiency and tolerance of mitotane in Cushing's disease in 76 patients from a single center. European Journal of Endocrinology 167(4), 473-481 (2012). https://doi. org/10.1530/EJE-12-0358

87. P. Igaz, Z. Tombol, P.M. Szabo, I. Liko, K. Racz, Steroid biosynthesis inhibitors in the therapy of hypercortisolism: Theory and practice. Current Medicinal Chemistry 15, 2734-2747 (2008)

88. J.E. Greening, Efficient short-term control of hypercortisolaemia by low-dose etomidate in severe paediatric Cushing's disease. Hormone Research in Paediatrics 64(3), 140-143 (2005)

89. R. Pivonello, M.C. De Martino, P. Cappabianca, M. De Leo, A. Faggiano, G. Lombardi et al. The medical treatment of Cushing's disease: effectiveness of chronic treatment with the dopamine agonist cabergoline in patients unsuccessfully treated by surgery. Journal of Clinical Endocrinology and Metabolism 94, 223-230 (2009). https://doi.org/10.1210/jc.2008-1533

90. M. Boscaro, W.H. Ludlam, B. Atkinson, J.E. Glusman, S. Petersenn, M. Reincke et al. Treatment of pituitary-dependent Cushing's disease with the multireceptor ligand somatostatin analog pasireotide (SOM230): a multicenter, phase II trial. Journal of Clinical Endocrinology and Metabolism 94, 115-122 (2009). https://doi.org/10.1210/jc.2008-1008

91. C. De Bruin, A.M. Pereira, R.A. Feelders, J.A. Romijn, F. Roelfsema, D.M. Sprij-Mooij et al. Coexpression of dopamine and somatostatin receptor subtypes in corticotroph adenomas. Journal of Clinical Endocrinology and Metabolism 94, 1118-1124 (2009). https://doi.org/10.1210/jc.2008-2101

92. D.L. Batista, X. Zhang, R. Gejman, P.J. Ansell, Y. Zhou, S.A. Johnson, The effects of SOM230 on cell proliferation and adrenocorticotropin secretion in human corticotroph pituitary adenomas. Journal of Clinical Endocrinology and Metabolism 91, 4482-4488 (2006)

93. R. Pivonello, D. Ferone, W.W. de Herder, Dopamine receptor expression and function in corticotroph pituitary tumors. Journal of Clinical Endocrinology and Metabolism 89, 2452-2462 (2004)

94. R.A. Feelders, C. de Bruin, A.M. Pereira, J.A. Romijn, R.T. Netea-Maier, A.R. Hermus et al. Pasireotide alone or with cabergoline and ketoconazole in Cushing's disease. New 
England Journal of Medicine 362, 1846-1848 (2010). https://doi. org/10.1056/NEJMc1000094

95. S. Park, J. Kamegai, R.D. Kineman, Role of glucocorticoids in the regulation of pituitary somatostatin receptor subtype (sst1sst5) mRNA levels: evidence for direct and somatostatinmediated effects. Neuroendocrinology 78(3), 163-175 (2003). https://doi.org/10.1159/000072798

96. A. Colao, S. Petersen, J. Newell-Price, J.W. Findling, F. Gu, M. Maldonado et al. A 12-month phase 3study of pasireotide in Cushing's disease. New England Journal of Medicine 366, 914-924 (2012)

97. F. Ceccato, C. Scaroni, M. Boscaro, Clinical use of pasireotide for Cushing's disease in adults. Therapeutics and Clinical Risk Management 11, 425-434 (2015)

98. M. Fleseriu, B.M. Biller, J.W. Findling, M.E. Molitch, D.E. Schteingart, C. Gross et al. Mifepristone, a glucocorticoid receptor antagonist, produces clinical and metabolic benefits in patients with Cushing's syndrome. Journal of Clinical Endocrinology and Metabolism 97(6), 2039-49 (2012). https://doi.org/ 10.1210/jc.2011-3350

99. R.S. Newfield, I.M. Spitz, C. Isacson, M.I. New, Long-term mifepristone (RU486) therapy resulting in massive benign endometrial hyperplasia. Clinical Endocrinology 54, 399-404 (2001)

100. T.M. Barber, E. Adams, J.A. Wass, Nelson syndrome: definition and management. Handbook of Clinical Neurology 124, 327-37 (2014). https://doi.org/10.1016/B978-0-444-59602-4.00022-8

101. S.K. Nagesser, A.P. van Seters, J. Kievit, J. Hermans, H.M. Krans, C.J. van de Velde, Long-term results of total adrenalectomy for Cushing's disease. World Journal of Surgery 24, 108-113 (2000). https://doi.org/10.1007/s002689910020

102. N.J. Hopwood, F.M. Kenny, Incidence of Nelson's syndrome after adrenalectomy for Cushing's disease in children: results of a nationwide survey. American Journal of Diseases of Children 131, 1353-1356 (1977)

103. C.G. Thomas, A.T. Smith, M. Benson, J. Griffith, Nelson's syndrome after Cushing's disease in childhood: a continuing problem. Surgery 96, 1067-1077 (1984)

104. de Oliveira, R.S., de Castro, Mo, Rauber S.R., Martinelli, C.E. Jr., Moreira, A.C., Machado, H.R.: Surgical management of pediatric Cushing's disease: an analysis of 15 consecutive cases at a specialized neurosurgical center. Arq BrasEndocrinol Metab (2010) https://doi.org/10.1590/S0004-27302010000100004

105. T.M. Barber, E. Adams, O. Ansorge, J.V. Byrne, N. Karavitaki, J.A. Wass, Nelson's syndrome. European Journal of Endocrinology 163(4), 495-507 (2010)

106. A.H. Heald, S. Ghosh, S. Bray, Long-term negative impact on quality of life in patients with successfully treated Cushing's disease. Clinical Endocrinology 61, 458-465 (2004). https://doi. org/10.1111/j.1365-2265.2004.02118.x

107. M.O. Van Aken, A.M. Pereira, N.R. Biermasz, Quality of life in patients after long-term biochemical cure of Cushing's disease. Journal of Clinical Endocrinology and Metabolism 90, 3279-3286 (2005)

108. A.A. van der Klaauw, M. Kars, N.R. Biermasz, F. Roelfsema, O. M. Dekkers, E.P. Corssmit et al. Disease-specific impairments in quality of life during long-term follow-up of patients with different pituitary adenomas. Clinical Endocrinology 69, 775-784 (2008). https://doi.org/10.1111/j.1365-2265.2008.03288.x
109. J. Tiemensma, N.E. Kokshoorn, N.R. Biermasz, B.J. Keijser, M. J. Wassenaar, H.A. Middelkoop et al. Subtle cognitive impairments in patients with long-term cure of Cushing's disease. Journal of Clinical Endocrinology and Metabolism 95, 2699-2714 (2010). https://doi.org/10.1210/jc.2009-2032

110. M.A. Wagenmakers, R.T. Netea-Maier, J.B. Prins, T. Dekkers, M. den Heijer, A.R. Hermus et al. Impaired quality of life in patients in long-term remission of Cushing's syndrome of both adrenal and pituitary origin: a remaining effect of long-standing hypercortisolism? European Journal of Endocrinology 167, 687-695 (2012). https://doi.org/10.1530/EJE-12-0308

111. M.F. Keil, D.P. Merke, R. Gandhi et al. Quality of life in children and adolescents 1-year after cure of Cushing syndrome: a prospective study. Clinical Endocrinology 71, 326-333 (2009)

112. F. Pecori Giraldi, M. Moro, F. Cavagnini; Study Group on the Hypothalamo-Pituitary-Adrenal Axis of the Italian Society of Endocrinology, Gender-related differences in the presentation and course of Cushing's disease. Journal of Clinical Endocrinology and Metabolism 88(4), 1554-1558 (2003)

113. D.A. Rees, F.W. Hanna, J.S. Davies, R.G. Mills, J. Vafidis, M.F. Scanlon, Long-term follow-up results of transsphenoidal surgery for Cushing's disease in a single centre using strict criteria for remission. Clinical Endocrinology 56(4), 541-551 (2002)

114. G. Rollin, N.P. Ferreira, M.A. Czepielewski, Prospective evaluation of transsphenoidal pituitary surgery in 108 patients with Cushing's disease. Arquivos Brasileiros de Endocrinologia and Metabologia 51(8), 1355-1361 (2007)

115. D.M. Prevedello, N. Pouratian, J. Sherman, J.A. Jane Jr., M.L. Vance, M.B. Lopes et al. Management of Cushing's disease: outcome in patients with microadenoma detected on pituitary magnetic resonance imaging. Journal of Neurosurgery 109(4), 751-759 (2008). https://doi.org/10.3171/JNS/2008/109/10/0751

116. R. Valero, S. Vallette-Kasic, B. Conte-Devolx, P. Jaquet, T. Brue, The desmopressin test as a predictive factor of outcome after pituitary surgery for Cushing's disease. European Journal of Endocrinology 151(6), 727-733 (2004)

117. S. Cannavò, B. Almoto, C. Dall'Asta, S. Corsello, R.M. Lovicu, E. De Menis et al. Long-term results of treatment in patients with ACTH-secreting pituitary macroadenomas. European Journal of Endocrinology 149(3), 195-200 (2003)

118. D. Bochicchio, M. Losa, M. Buchfelder, Factors influencing the immediate and late outcome of Cushing's disease treated by transsphenoidal surgery: a retrospective study by the European Cushing's Disease Survey Group. Journal of Clinical Endocrinology and Metabolism 80(11), 3114-3120 (1995)

119. C.A. Carrasco, J. Coste, L. Guignat, Midnight salivary cortisol determination for assessing the outcome of transsphenoidal surgery in Cushing's disease. Journal of Clinical Endocrinology and Metabolism 93(12), 4728-4734 (2008). https://doi.org/10.1210/ jc. 2008-1171

120. N. Sonino, M. Zielezny, G.A. Fava, F. Fallo, M. Boscaro, Risk factors and long-term outcome in pituitary-dependent Cushing's disease. Journal of Clinical Endocrinology and Metabolism 81 (7), 2647-52 (1996). https://doi.org/10.1210/jcem.81.7.8675592

121. K. Hague, K.D. Post, S. Morgello, Absence of peritumoral Crooke's change is associated with recurrence in surgically treated Cushing's disease. Surgical Neurology 53(1), 77-81 (2000) 